\title{
Investigations about the Effects and Effectiveness of Adaptivity for Students with different Learning Styles*
}

\author{
Sabine Graf ${ }^{1}$, Chung Hsien Lan ${ }^{2}$, Tzu-Chien Liu ${ }^{3}$, Kinshuk ${ }^{1}$ \\ ${ }^{1}$ Athabasca University, Canada, sabine.graf@ieee.org,kinshuk@ieee.org \\ ${ }^{2}$ Nanya Institute of Technology, Taiwan, chlan@nanya.edu.tw \\ ${ }^{3}$ National Central University, Taiwan, ltc@cc.ncu.edu.tw
}

\begin{abstract}
Considering learning styles in technology enhanced learning seems to be a promising concept for making learning easier for students. However, contradictory opinions exist on this issue. In this paper, we aim at investigating the possible benefits of providing students with courses that fit their learning styles based on the Felder-Silverman learning style model, showing whether and for whom adaptivity can be helpful, how it can support students, and how effective adaptivity can be for students with particular learning styles. The results of the analysis, conducted with data from 147 students, showed that students with different learning styles benefit from adaptivity in different ways and extents. The findings provide deeper insights and help in understanding the effects and effectiveness of adaptive courses, considering different learning styles.
\end{abstract}

\section{Introduction}

Many different learning style models exist in literature [e.g., 1, 2, 3], arguing that students prefer to learn in different ways. Furthermore, many educational theorists agree that considering students' learning styles has potential to make learning easier for them. Based on these arguments, several adaptive systems considering learning styles have been developed [e.g., $4,5,6]$ and several evaluations of such systems have been conducted [e.g., 4, 7, 8]. Some of these evaluations confirmed that adaptivity can help students in learning, while others did not find evidence for it.

Most evaluations mainly aimed at proving whether or not the adaptive systems were able to support students in learning, rather than investigating the effects and effectiveness of adaptivity for learners with

\footnotetext{
* Authors acknowledge the support of Austrian Science Fund (FWF) under grant J2831-N13, National Science Council of the Republic of China, Taiwan, under Contract No. NSC 96-2520-S-008-007-MY2, NSC 097-2811-S-008-001-, and NSC 97-2631-S-008-003-, iCORE, Xerox, and the research related gift funding by Mr. A. Markin.
}

different learning styles. In this paper, we aim at investigating the advantages of adaptive courses in more detail, showing which students can benefit from adaptivity and how adaptive courses can affect their learning. More concretely, we focus on answering two research questions: First, we investigate whether and how students with different learning styles benefit from adaptive courses in terms of their performance and behaviour. Second, we look at which students can be supported more effectively by using adaptivity, considering their learning styles.

This study is based on and uses data from a project about providing adaptivity in learning management systems (LMSs). In this project, a concept for providing adaptivity in LMSs has been designed, implemented in Moodle [9] and evaluated with 437 students $[4,10]$. Section 2 describes this concept in more detail. Subsequently, we present the study design, method of data analysis, and results and discussion of our study. Finally, we present our conclusions and future research directions.

\section{A concept for providing adaptivity}

This study is based on a concept for providing adaptivity in LMSs with respect to the FelderSilverman learning style model (FSLSM) [1]. FSLSM describes learning styles in very much detail and is therefore highly appropriate for providing adaptivity as well as for analysing the effects and effectiveness of adaptivity. Furthermore, the FSLSM is based on the concept of tendencies, allowing handling of exceptional behaviour by considering learning styles as a main tendency rather than as an obligatory type. Moreover, FSLSM is one of the most often used learning style models in technology enhanced learning.

According to FSLSM, each learner has a preference for each of its four dimensions (active/reflective, sensing/intuitive, visual/verbal, sequential/global). Active learners prefer to learn by trying things out and working with others, whereas reflective learners prefer 
to learn by thinking things through and working alone. Sensing learners like to learn from concrete material like examples and tend to be more practical and more careful with details, whereas intuitive learners prefer to learn abstract material, tend to be more innovative, and like challenges. Visual learners remember best what they have seen, whereas verbal learners get more out of words, regardless of whether they are spoken or written. Sequential learners learn in linear steps and prefer to be guided through the learning process, whereas global learners learn in large leaps and prefer more freedom in their learning process.

The concept for providing adaptivity based on learning styles aims at enabling LMSs to automatically generate courses that fit the students' learning styles based on the FSLSM. Since a main concern was to keep the concept simple to use for teachers and ask them for as little as possible additional effort, only the active/reflective, sensing/intuitive, and sequential/ global dimensions have been included. The visual/verbal dimension was excluded since this dimension asks for different presentation modes, for example, including text, audio files, and video files, which are time-consuming in their development.

The concept is based on the assumption that a course consists of several chapters, where for each chapter, adaptivity can be provided. Each chapter includes an outline of the presented topics as well as a conclusion that summarises the most important aspects of the chapter. For presenting the content of the course, content objects are considered, which are pages that include the relevant learning material. Furthermore, examples are incorporated, which are used for better illustration and provide students with more concrete material. Moreover, students can check their acquired knowledge by the use of self-assessment tests. Another element includes exercises, which serve as practice area where students can try things out or answer questions about interpreting predefined solutions or developing new solutions.

Adaptivity is provided on a general basis, adapting courses with respect to the sequence and the number of the above introduced types of learning objects (LOs). For example, learners with an active learning style are presented with a higher number of exercises since they prefer to work actively with the learning material. Another example is to present learners with a sensing learning style with examples before showing them the more abstract content objects in order to help them to get more concrete information first. A detailed description about how courses are adapted for each learning style can be found in [10].

It should be mentioned at this point that the basic idea of the proposed concept is to provide students with a recommended course; however, students have always the possibility to see all available LOs and visit them in any sequence they prefer.

The proposed concept has been evaluated with respect to its effectiveness in supporting students and showed that the concept was successful in helping students to learn more effectively $[4,10]$. However, the performed evaluation provided only a general insight about the effectiveness of the concept, showing that it helps students in general. In the following study, more detailed investigations are conducted in order to find out the effects and effectiveness of adaptivity for students with different learning styles.

\section{Study design}

In the abovementioned project for enriching LMSs with adaptivity, learners were divided into three groups and presented either with a course that matched their learning styles (matched group), did not match their learning styles (mismatched group), or included all LOs independent of the students' learning styles (standard group). In the current study, only data from the matched and mismatched group are used in order to analyse in more detail the benefits of providing adaptivity for learners with different learning styles.

Data were gathered from a course about object oriented modelling, which was taught to undergraduate students in the second semester of Information Systems and Computer Science curriculum at a university in Austria. The course consisted of a lecture and a practical part, where students had to submit 5 assignments. The whole course was managed via Moodle, which was extended by the concept for providing adaptivity introduced in Section 2. The online course consisted of 7 chapters, which included the types of LOs proposed above.

When students registered in Moodle, they were asked to fill out the Index of Learning Styles (ILS) questionnaire [11], which is an instrument for detecting students' learning styles based on the FSLSM. When the students logged in to the course, Moodle automatically presented the course according to the assigned group and the students' learning styles respectively. However, the presented course acted as a recommendation. Independent of the assigned group, students had the possibility to ask for and access all LOs via a link at the overview page of the course. This option was explicitly pointed out when introducing the course in the first lesson.

\section{Method of data analysis}

In order to ensure reliable data, the students had to spend more than 5 minutes on filling out the ILS questionnaire in order to include their data in our 
Table 1: Means and standard deviations for each learning style and group

\begin{tabular}{|c|c|c|c|c|c|c|c|c|c|c|c|c|c|}
\hline \multirow{2}{*}{\multicolumn{2}{|c|}{ stude }} & \multicolumn{2}{|c|}{$\begin{array}{c}\text { active } \\
\text { matched mismatched }\end{array}$} & \multicolumn{2}{|c|}{$\begin{array}{c}\text { reflective } \\
\text { matched mismatched }\end{array}$} & \multicolumn{2}{|c|}{$\begin{array}{c}\text { sensing } \\
\text { matched mismatched }\end{array}$} & \multicolumn{2}{|c|}{$\begin{array}{c}\text { intuitive } \\
\text { matched mismatched }\end{array}$} & \multicolumn{2}{|c|}{$\begin{array}{c}\text { sequential } \\
\text { matched mismatched }\end{array}$} & \multicolumn{2}{|c|}{$\begin{array}{c}\text { global } \\
\text { matched mismatched } \\
\end{array}$} \\
\hline & & 41 & 38 & 34 & 34 & 47 & 47 & 28 & 25 & 35 & 36 & 40 & 36 \\
\hline final exam & mean & 166.07 & 176.18 & 184.37 & 188.32 & 169.98 & 181.70 & 185.43 & 182.32 & 173.20 & 180.11 & 177.98 & 183.72 \\
\hline & std. & 28.76 & 30.82 & 20.39 & 25.94 & 30.22 & 29.57 & 25.54 & 28.71 & 34.24 & 31.12 & 24.57 & 27.18 \\
\hline time & mean & 3.81 & 6.00 & 6.68 & 4.58 & 4.77 & 5.86 & 4.67 & 5.10 & 4.45 & 6.29 & 4.76 & 4.90 \\
\hline (in hours) & std. & 1.96 & 4.13 & 5.56 & 2.51 & 3.25 & 4.28 & 2.72 & 2.63 & 2.57 & 4.34 & 3.18 & 3.04 \\
\hline numlogin & $\begin{array}{l}\text { mean } \\
\text { std. }\end{array}$ & $\begin{array}{l}27.24 \\
7.13\end{array}$ & $\begin{array}{l}31.44 \\
9.93\end{array}$ & $\begin{array}{l}31.08 \\
6.55\end{array}$ & $\begin{array}{l}30.27 \\
10.85\end{array}$ & $\begin{array}{c}27.86 \\
6.85\end{array}$ & $\begin{array}{l}30.26 \\
10.99\end{array}$ & $\begin{array}{l}32.22 \\
10.86\end{array}$ & $\begin{array}{c}31.91 \\
9.19\end{array}$ & $\begin{array}{l}33.44 \\
11.78\end{array}$ & $\begin{array}{l}37.29 \\
14.81\end{array}$ & $\begin{array}{l}29.12 \\
9.37\end{array}$ & $\begin{array}{l}28.87 \\
7.14\end{array}$ \\
\hline numLO & $\begin{array}{l}\text { mean } \\
\text { std. }\end{array}$ & $\begin{array}{l}415.21 \\
209.49\end{array}$ & $\begin{array}{l}486.17 \\
276.83 \\
\end{array}$ & $\begin{array}{l}624.73 \\
448.58 \\
\end{array}$ & $\begin{array}{l}433.83 \\
193.95 \\
\end{array}$ & $\begin{array}{l}413.33 \\
225.81\end{array}$ & $\begin{array}{l}545.17 \\
350.18 \\
\end{array}$ & $\begin{array}{l}486.22 \\
278.84\end{array}$ & $\begin{array}{l}438.04 \\
177.69\end{array}$ & $\begin{array}{l}465.78 \\
246.85\end{array}$ & $\begin{array}{l}574.69 \\
344.72 \\
\end{array}$ & $\begin{array}{l}461.86 \\
297.74\end{array}$ & $\begin{array}{l}1.17 \\
429.06 \\
199.21\end{array}$ \\
\hline numALO_p & $\begin{array}{l}\text { mean } \\
\text { std. }\end{array}$ & $\begin{array}{l}7.10 \\
4.40\end{array}$ & $\begin{array}{l}8.56 \\
6.17\end{array}$ & $\begin{array}{l}5.46 \\
4.22\end{array}$ & $\begin{array}{l}7.91 \\
5.17\end{array}$ & $\begin{array}{l}6.07 \\
4.08\end{array}$ & $\begin{array}{l}8.27 \\
5.74\end{array}$ & $\begin{array}{l}6.44 \\
4.39\end{array}$ & $\begin{array}{l}8.23 \\
5.71\end{array}$ & $\begin{array}{l}6.49 \\
4.49\end{array}$ & $\begin{array}{l}7.51 \\
5.79\end{array}$ & $\begin{array}{l}6.25 \\
4.31\end{array}$ & $\begin{array}{l}8.99 \\
5.56\end{array}$ \\
\hline
\end{tabular}

study. Moreover, we included only data from students who submitted at least 3 assignments and performed the final exam which both were requirements for passing the course. From the overall 437 students, data from 75 students in the matched group and 72 students in the mismatched group fulfilled the abovementioned requirements and were therefore included in our study.

For answering the first research question, namely whether and how students with different learning styles can benefit from adaptivity in terms of their performance and behaviour, data from the matched and mismatched group were compared. To get information about students' performance, the scores of the final exam were used. For more detailed information regarding their behaviour, four patterns were considered: the time students spent in the course (time), the number of logins (numlogin), the number of visited LOs (numLO), and the number of times a student asked for additional, not recommended LOs in relation to the overall number of visited LOs (numALO p). For each performance and behaviour variable, one-way ANOVA was used to find a difference between students from the matched and mismatched group. Outliers were excluded for each group and variable.

The second research question focuses on comparing the effectiveness of adaptivity for students with different learning styles. Therefore, only data from students in the matched group were considered. We looked again at differences regarding the five performance and behaviour variables described above. For each of these variables, one-way ANOVA was used in order to find out whether learners with different learning styles performed and behaved differently in the adaptive course, comparing the two learning styles of each learning style dimension respectively. Again, outliers were excluded for each group and variable.

\section{Results and discussion}

In the next two subsections, the results of the analysis for each research question are described and discussed. Table 1 provides descriptive data for both analyses, showing the means and standard deviations for each learning style and each group.

\subsection{Effects of adaptivity for students with different learning styles}

The first research question aims at investigating whether and how adaptivity can improve students' performance and/or change their behaviour in a course, considering students' learning styles. Table 2 presents the $F$ values $(F)$ and significance values ( $p$ ) of one-way ANOVA, indicating significant differences between students' from the matched and mismatched group with an asterisk, using a significance level of 0.05 .

As can be seen, no significant differences were found for the students' performance with respect to all six learning styles. However, differences in the students' behaviour and efforts could be found, which are different for students with different learning styles.

Results show that active learners in the mismatched course spent more time in the course in order to get similar scores than active learners in the matched course. According to FSLSM, active learners like to work actively with the material and try things out. We found that their interest for exploring the course and looking at additional LOs was for both, learners in a matched and mismatched course, quite high compared to learners with other learning styles. However, as a general strategy, active learners in the mismatched group seem to compensate by spending more time in the course in order to get similar scores as learners from the matched group.

For reflective learners, we found a significant difference between learners from the matched and mismatched group for the number of times they asked

Table 2: Differences between matched and mismatched groups for each learning style

\begin{tabular}{|l|c|cccccc|}
\hline & & active & reflective & sensing & intuitive & sequential & global \\
\hline final_exam & $\mathrm{F}$ & 2.276 & 0.451 & 3.613 & 0.174 & 0.793 & 0.937 \\
& $\mathrm{p}$ & 0.136 & 0.504 & 0.06 & 0.678 & 0.376 & 0.336 \\
\hline time & $\mathrm{F}$ & $7.888^{*}$ & 3.856 & 1.754 & 0.339 & $4.271^{*}$ & 0.038 \\
& $\mathrm{p}$ & 0.006 & 0.054 & 0.189 & 0.563 & 0.043 & 0.846 \\
\hline numlogin & $\mathrm{F}$ & 3.937 & 0.11 & 1.28 & 0.012 & 1.356 & 0.014 \\
& $\mathrm{p}$ & 0.052 & 0.741 & 0.262 & 0.915 & 0.249 & 0.906 \\
\hline numLO & $\mathrm{F}$ & 1.54 & $4.639^{*}$ & $4.084^{*}$ & 0.509 & 2.173 & 0.29 \\
& $\mathrm{p}$ & 0.219 & 0.035 & 0.047 & 0.479 & 0.145 & 0.592 \\
\hline numALO_p & $\mathrm{F}$ & 1.486 & $4.531^{*}$ & $4.442^{*}$ & 1.668 & 0.867 & $5.741^{*}$ \\
& $\mathrm{p}$ & 0.227 & 0.037 & 0.038 & 0.202 & 0.41 & 0.019 \\
\hline
\end{tabular}


for additional LOs but not for the time they spent in the course. We can interpret these results in a way that reflective learners in the matched group were more satisfied with their course. On the other hand, reflective learners from the mismatched group seemed to realise that the recommended course did not fit their preferred way of learning and therefore searched significantly more often for additional, more suitable LOs. We also found that learners from the matched group looked overall at more LOs than learners from the mismatched group, which might indicate that learners from the mismatched group looked at some additional LOs instead of visiting all the recommended LOs, which resulted overall in a lower number of visited LOs.

Similar results could be found for sensing learners. Again, sensing learners from the mismatched group asked significantly more often for additional LOs than learners from the matched group, indicating that sensing learners seems to be more aware of how they prefer to learn. Furthermore, we found that sensing learners in the mismatched group visited significantly more LOs than learners from the matched group. While reflective learners looked at additional LOs instead of the recommended ones, sensing learners seem to look at them additionally. This is in line with the characteristics of sensing learners according to FSLSM, since sensing learners tend to be more careful and therefore would likely prefer to take also a look at the recommended LOs.

For intuitive learners, we found no significant difference for the behaviour of students in the matched and mismatched groups. It seems that adaptivity had only little impact on the students' behaviour and performance. This might be explained by the characteristics of intuitive learners, who like challenges and finding new ways of doing something and therefore, might also be able to learn well from a mismatched course.

Similar to active learners, sequential learners from the mismatched group spent more time in the course than sequential learners from the matched group for getting similar scores. This is in line with FSLSM, since sequential learners prefer to go through the learning material in a sequential way, without skipping or adding LOs, and tend to rely on guidance in their learning process. Therefore, sequential learners in the mismatched course seem to follow the recommended LOs but needed more time to learn from them.

For global learners, the opposite is true. They prefer to have freedom in their learning process and to decide by themselves which LOs are suitable for them. This is also reflected in the results, showing that global learners from the mismatched group asked significantly more often for additional LOs. On the other hand, global learners from the matched group seem to be satisfied with the recommended LOs and asked for additional LOs less often.

\subsection{Effectiveness of adaptivity comparing different learning styles}

The second research question deals with investigating the effectiveness of adaptivity with respect to different learning styles, showing whether students with different learning styles have different performance and behaviour in a matched course and therefore indicating which learning styles can be supported better than others by providing adaptivity. Table 3 presents the $F$ values $(F)$ and significance values (p) of one-way ANOVA, highlighting significant results with an asterisk, using a significance level of 0.05 .

When looking at the behaviour and performance in the matched course, we found that reflective learners spent more time in the course, logged in more often, visited more LOs, and got better scores than active learners. In order to verify that these results are due to providing adaptivity rather than a general pattern for active and reflective learners, we additionally analysed data from the mismatched group accordingly and did not find a significant difference between active and reflective learners for any performance or behaviour pattern (final_exam: $\mathrm{F}=3.227, \mathrm{p}=0.077$; time: $\mathrm{F}=2.879$, $\mathrm{p}=0.094$; numlogin: $\mathrm{F}=0.197, \mathrm{p}=0.659$; numLO: $\mathrm{F}=$ $0.754, \mathrm{p}=0.388$ ). Thus, we can conclude that reflective learners were more motivated and encouraged by the matched course than active learners, so that they used the course more intensively and therefore also got better scores.

Regarding the sensing/intuitive dimension, no difference was found for the behaviour patterns. However, it can be seen from the results that intuitive learners yielded better results in matched courses than sensing learners. When looking at the mismatched course, this difference could not be found $(\mathrm{F}=0.007$, $\mathrm{p}=0.932$ ), confirming that the difference is due to providing adaptivity. Therefore, we can conclude that while the matched course did not yield to different

\section{Table 3: Differences between learning styles} for the matched group

\begin{tabular}{|l|l|lll|}
\hline & & act/ref & sen/int & seq/glo \\
\hline final_exam & $\mathrm{F}$ & $8.862^{*}$ & $5.127^{*}$ & 0.490 \\
& $\mathrm{p}$ & $0.004^{*}$ & 0.027 & 0.486 \\
\hline time & $\mathrm{F}$ & $8.063^{*}$ & 0.018 & 0.180 \\
& $\mathrm{p}$ & $0.006^{*}$ & 0.893 & 0.672 \\
\hline numlogin & $\mathrm{F}$ & $4.586^{*}$ & 3.866 & 2.806 \\
& $\mathrm{p}$ & $0.036^{*}$ & 0.054 & 0.099 \\
\hline numLO & $\mathrm{F}$ & $6.635^{*}$ & 1.370 & 0.003 \\
& $\mathrm{p}$ & 0.012 & 0.246 & 0.953 \\
\hline numALO_p & $\mathrm{F}$ & 2.649 & 0.131 & 0.055 \\
& $\mathrm{p}$ & 0.108 & 0.718 & 0.816 \\
\hline
\end{tabular}


behaviour between sensing and intuitive learners, intuitive learners seem to be supported better than sensing learners due to their better scores.

For sequential and global learners, the matched course seems to work similarly well for both types of learning styles. Students showed similar scores and similar behaviour with respect to all variables.

\section{Conclusions and Future Work}

This paper presented an analysis about the effects and effectiveness of adaptivity with respect to learning styles. A concept for providing adaptivity in LMSs was used as the basis for this study. The concept was already evaluated in a general way $[4,10]$, demonstrating that it was successful in supporting students in learning. The aim of this study was to get deeper insights into how students can benefit from adaptivity, considering their learning styles.

First, we looked at the effects of courses that are matched to students' learning styles, compared to mismatched courses. The results showed no significant difference with respect to students' performance. However, they showed clearly that differences exist between students from matched and mismatched courses with respect to their behaviour and that these differences varied for students with different learning styles. In general, two strategies can be seen: Active and sequential learners can benefit from adaptivity by spending less time in the course than they would in a course that does not match their learning styles. On the other hand, reflective, sensing, and global learners in a matched course use this course more often as it is, whereas they search more often for more suitable LOs if they are presented with a mismatched course. For intuitive learners, no different behaviour has been found. Overall, these findings demonstrate that adaptivity based on learning styles can support learners and lead to the assumption that it has different effects for learners with different learning styles. The findings give a deeper insight into the potential of adaptivity with respect to learning styles as well as into how students try to compensate a mismatched course.

Second, we investigated the effectiveness of adaptive courses by comparing the performance and behaviour of students with different learning styles. Results showed that differences exist between active and reflective learners, and between sensing and intuitive learners. On the other hand, sequential and global learners achieved similar scores and behaved similarly in the matched course. Overall, the findings show that for some learning styles adaptivity works better than for others, in terms of encouraging them to use the course more intensively and/or letting them achieve better scores. The findings give a deeper insight in the effectiveness of adaptivity for different learning styles, showing again that students with different learning styles can benefit differently from adaptivity.

Future work will deal with a more detailed analysis, investigating the interactions of the three learning style dimensions with each other as well as whether there exist combinations of learning styles which have more impact for supporting students. Furthermore, we plan to investigate to which extent the results of our study are depending on the concept for providing adaptivity and therefore show only possible benefits of adaptivity or whether these results appear in general when adaptivity is provided.

\section{References}

[1] R. M. Felder and L. K. Silverman, Learning and teaching styles in engineering education, Engineering Education, 78, 1988, pp. 674-681.

[2] P. Honey and A. Mumford, The manual of learning styles, Peter Honey, Maidenhead, 1982.

[3] D. A. Kolb, Experiential learning: Experience as the source of learning and development, Prentice-Hall, Englewood Cliffs, New Jersey, 1984.

[4] S. Graf and Kinshuk, Providing Adaptive Courses in Learning Management Systems with Respect to Learning Styles, Proceedings of the World Conference on E-Learning in Corporate, Government, Healthcare, and Higher Education, AACE Press, 2007, pp. 25762583.

[5] P. Paredes and P. Rodríguez, A mixed approach to modelling learning styles in adaptive educational hypermedia, Advanced Technology for Learning, 1, 2004, pp. 210-215.

[6] N. Stash, A. Cristea and P. de Bra, Adaptation to learning styles in e-learning: Approach evaluation, Proceedings of World Conference on E-Learning in Corporate, Government, Healthcare, and Higher Education, AACE Press, 2006, pp. 284-291.

[7] N. Bajraktarevic, W. Hall and P. Fullick, Incorporating learning styles in hypermedia environment: Empirical evaluation, Proceedings of the Workshop on Adaptive Hypermedia and Adaptive Web-Based Systems, Eindhoven University, Nottingham, 2003, pp. 41-52.

[8] E. Brown, T. Brailsford, T. Fisher, A. Moore and H. Ashman, Reappraising cognitive styles in adaptive web applications, Proceedings of the International World Wide Web Conference, ACM Press, 2006, pp. 327-335.

[9] Moodle, 2009. Retrieved 15 January, 2009, from http://www.moodle.org

[10] S. Graf, Adaptivity in Learning Management Systems focussing on Learning Styles, PhD Thesis, Vienna University of Technology, 2007.

[11] R. M. Felder and B. A. Soloman, 1997. Index of Learning Styles questionnaire. Retrieved 15 January, 2009, from http://www.engr.ncsu.edu/learningstyles/ ilsweb.html 